Accepted by Child and Family Social Work 23rd April 2016

\title{
Risk, resilience and identity construction in the life narratives of young people leaving residential care
}

\author{
Gillian Schofield, Birgit Larsson and Emma Ward
}

\begin{abstract}
The role of residential care for children has developed very differently internationally, but in all cultural contexts there are questions about the extent to which it can help young people recover from high risk backgrounds. In the UK, residential care has come to be seen as the placement of last resort, yet new government guidance on permanence has suggested that residential care can provide security and a sense of belonging. Narrative analysis of interviews with 20 care leavers identified their different pathways from birth families through residential care to early adulthood. Some experienced a transformation from a negative sense of self as victims or 'bad children' to survivors, while others continued to struggle. Key to successful turning points were four interacting factors, all associated with resilience; connection, agency, activity and coherence. These narratives revealed the importance of nurturing relationships and a sense of 'family', but also the role of support after leaving residential care, when transitions workers helped them to move on but stay connected. The study highlighted how residential care leavers from adverse backgrounds attribute very different meanings to their experiences, which affects identity construction, resilience and the need for support.
\end{abstract}

Key words: risk; resilience; identity; transitions; residential care 


\section{Introduction}

The role of residential care for children has developed very differently internationally, both in the numbers and characteristics of children placed and the perceived purpose of the placement (Thoburn and Ainsworth 2014). But in all cultural contexts, there are questions about the extent to which residential care environments can provide an experience for young people from high risk backgrounds that helps them to overcome adversity and meets their need to develop security, resilience and a sense of belonging. The need to promote young people's resilience (Gilligan 1999; Rutter 2013; Masten 2014) becomes a particular issue at the point of transition to adulthood when 'leaving care' (in the UK, at or before age 18) is expected to mean leaving the care of the residential home and its staff with the expectation of becoming 'independent' (Stein 2012). The key research question for this study of care leavers' narratives was to explore the different experiences and meanings associated with their pathways from troubled birth families through residential care and into early adulthood, including their perception of the support they received.

\section{Policy and research on residential care}

Unlike many other countries in Europe (Thoburn and Ainsworth 2014), residential care in children's homes in the UK is the placement for only a small percentage (8\% in 201415) of looked after children (Department of Education 2015a). The role of residential care in the UK has therefore become predominantly to provide placements for children with special needs, for older children and for children whose needs have not been able to be met in foster care. Although residential care has come to be seen as the placement of last resort, recent government guidance on achieving permanence for children (Department for Education 2015b: para 2.6) has suggested that residential care can provide 'a sense of security and belonging'. 
A number of concerns about outcomes for children in care generally have been seen as specifically challenging in residential care. For example, there are high levels of diagnosable mental health disorders (46\%) among looked after children, but particularly high levels (68\%) in residential care (Meltzer et al 2000). Low educational attainment is a particular issue for children in residential care and Berridge et al (2012) reported that only $41 \%$ of children in residential care had been in mainstream school in the previous 6 months.

The significance of warm, secure and continuous relationships for young people from troubled family backgrounds is apparent while they are in residential care (Berridge et al 2012, Kendrick 2013, Hart et al 2015). But continuity of relationships is especially valuable in the transition from care to adult life (Stein 2012,). Here there are tensions between the stated goal of the care system, to achieve 'permanence' and a sense of belonging (Department for Education 2015b), and the expectations around leaving care when young people are expected to move from children's homes into 'independence'. 'Staying Put' arrangements (Department for Education 2013) offer young people in foster care the opportunity to stay till age 21 , but this option is not available for the group who are probably the most vulnerable in the care system - young people in residential care (National Children's Bureau 2014).

\section{Risk, resilience and identity}

Concerns about outcomes from residential care need to be addressed through clarity about its goals. Inevitably for adolescents with complex and adverse histories there are questions about the extent to which as care leavers their emotional and behavioural difficulties have been resolved, and in particular whether they have a coherent identity and the necessary qualities, skills and coping strategies as they move from residential care in early adulthood. 
Resilience is a useful concept on which to focus these goals for children in residential care as it targets successful adaption to past, current and future challenges (Masten 2014). Resilience factors most at risk in a care population likely to have experienced maltreatment (Howe 2005), include self-esteem, self-efficacy and the capacity to build trusting relationships (Gilligan 1999; Schofield and Beek 2005; Rutter, 2013). Specific to this residential care population and linked to identity construction are particular challenges in generating coherent narratives of complex family and care experiences, including the stigma of residential care, which would allow them to resolve feelings about the past and move on.

The approach taken in this study to understanding these resilience processes (Rutter 2013) was to consider how young people's own life narratives reflected different pathways and meanings attached to relationship experiences and how those meanings affected their sense of self and capacity in residential care to become more resilient. This will help to fill the gap in the literature on how close relationships in residential care can contribute to a sense of security, permanence and belonging.

\section{The study}

The study involved an investigation of young people's experiences of the transition to adulthood from children's homes run by a voluntary sector organisation. The organisation provided care for young people in small children's homes (4-5 residents), with some staying $3-7$ years. The organisation was concerned that having experienced stability in their care, many young people's experience of leaving care was to face uncertain levels of support. Funding from the Esmée Fairbairn Foundation supported the development of a transitions team to work alongside residential staff to provide continuity of care and relationships into adulthood. As a new service, the 
transitions team contacted all young people up to the age of 30 who had left the children's homes to offer support. The message to young people currently leaving care was that support from the organisation would be available as long as needed.

\section{Methods}

The key research question concerned the nature of young people's experiences of pathways through birth families, care placements and transition into adulthood, involving complex patterns of movement between diverse caregiving environments; thus a narrative approach was used to investigate those experiences. It is only through understanding the young person's sense of their whole childhood, its cumulative and interactive nature, that identity construction and the experience of living in and moving on from residential care to independence can be understood. The project was approved by the - University of East Anglia Ethics Committee (Schofield et al 2015).

\section{The sample}

The interview sample was 20 young people aged 17- $26(17-19 n=13 ; 20-23 n=3 ; 24$ $26 n=4$ ) with 13 male and 7 female participants. All were white British, reflecting the predominant ethnicity of the area. At the time of the study there were 45-50 young people who were linked to the transitions team and young people were approached initially by staff. If the initial response was positive, young people would be contacted by a member of the research team to explain the project in more detail and obtain written consent. There were some young people not approached because of particular mental health or other vulnerabilities at the time of the study. Five young people who had expressed interest did not then complete interviews. The sample therefore cannot claim to be representative of all care leavers from this organisation, but provided diverse histories and a range of experiences, as the analysis will demonstrate. The 
interviews with young people were recorded, transcribed and analysed using narrative analysis.

\section{Narrative analysis}

Narrative methods focus on the stories that people tell, exploring the content and context (Freeman 2006; Phoenix 2013) , the meanings behind stories (McAdams 1993) and the way those stories are constructed (Mishler 1995). Narrative approaches underpinned this research project from the interviews with young people to the analysis, in order to provide a sense of participants' whole identities and how their sense of self might have changed over time (Riessman 1990; Crossley 2000; Holland et al, 2008). The process of analysis was inductive in being driven by the interview data, but the researchers also noted issues that the theory and research suggested were likely to be particularly salient for young people in a care setting, such as loss, family and belonging .

Many different types of narrative interview exist, ranging from structured forms that ask participants to imagine their lives as novels (McAdams 1993) to unstructured free narratives (Wengraf 2001). For this study, a semi-structured format was chosen (Riessman 1993: 55), which offered young people the flexibility to tell their story in their own way, but offered some structure and support.

The interview invited participants to generate narratives within chronological areas, including early years, school, going into care, previous placements, life in the children's home, leaving care, current lives and future plans. Although the interview schedule invited participants to tell their narratives in a chronological way (Mishler 1995), participants were encouraged to begin the story wherever they liked. Some young people chose to begin talking about their current situation first in order to place themselves for the researcher, and then went back to the beginning. 
The interviews were first read independently by two researchers for 'big stories,' or overarching meanings (Bamberg 2006; Freeman 2006; Phoenix 2013). In narrative theory, such 'big stories' have sometimes focused on participants' perceptions of their lives across time, such as Gergen and Gergen's (1983) description of participants' life stories as 'progressive,' 'regressive', or 'stable'. At other times, researchers have sought to classify participants as narrative types, depending on the themes, tone and imagery within their stories, such as McAdams' (1993:122) who searched for 'imagoes', or participants' 'personified and idealized concept (s) of the self'.

In this study, both approaches to analysis were taken in order to capture the nature of change and transformation over time and to identify different narrative types in a way that might help to understand young people's different pathways. To help with this process, the analysis also paid attention to narrative tone, metaphors and imagery (Freeman 2004). The researchers in particular searched for positive or negative turning points that might have changed the way participants saw themselves or the world around them (Gergen and Gergen 1983).

\section{Findings}

As interviews were analysed based on participants' sense of themselves over time, the narrative pathways which emerged reflected the extent and type of movement and change. Five pathways were identified from the data: love and loss to moving on $(\mathrm{n}=4)$; victim to survivor ( $\mathrm{n}=3)$; victim to struggling $(\mathrm{n}=3)$; 'bad child' to survivor $(\mathrm{n}=7)$; and 'bad child' to struggling $(\mathrm{n}=3)$.

The language for these transformed identities reflected the stories, but also reflected Stein's analysis of leaving care outcomes in terms of moving on, surviving and struggling 
(Stein, 2012). Additional pathway characteristics demonstrated important differences, including the significance of young people's different perceptions of themselves as young children. Such perceptions and continuity or change in those perceptions over time could reflect achieved resilience or unresolved vulnerabilities.

In making sense of the 20 narratives the analysis focused on young people's pathways from early childhood to the present. Certain themes emerged from this narrative analysis that helped to differentiate the narrative types:

- Connection: how young people described the quality of their relationships and sense of family and belonging with parents, relatives, peers, foster carers, children's home and transitions staff.

- Agency: the extent to which young people felt they had been and were currently able to exercise agency, make choices about their lives, influence events by their own actions.

- Constructive activity: how young people described their engagement with education, activities and the world of work.

- Coherence of the narrative: whether stories made sense and indicated that past experiences had been processed cognitively and feelings resolved to some degree.

\section{Love and loss to moving on}

\section{Narrative pathway}

These young people told stories that included some positive childhood experiences, in particular having at least one loving family caregiver. However, loss of caregivers, through death or separation, was accompanied by grief and led, ultimately, to the move into care. Foster care or other residential placements did not work out, for reasons generally perceived as linked to the placement and not to their own behaviour, and so they moved into the children's home. The home was a positive experience. These 
young people used their sense of agency to draw on other resources through connections with birth family, people at school or in the community.

As young people moved on from the children's home into adulthood, they had some resilience and social capital. Education and other constructive activities, such as sport, provided self-esteem and positive networks. Young people also told coherent stories that recognised past difficulties, but were mainly positive about self and others. They had prosocial strategies for managing their lives and seeking help flexibly from a range of people, including transitions workers. Agency and the need for connection to others were both present. Overall, they were achieving a balance between independence and interdependence and were capable of both giving and receiving in relationships.

In their interviews these young people who had experienced some positive emotional support in their birth families, attributed their successful move into adulthood primarily to instrumental outcomes, in particular the development of their education while in residential care, which they ascribed both to support received and to their own agency.

The football coach gave me that drive but failure at high school forced me to buck myself up and make sure that I got my grades up.

One young woman who had experienced many disruptions in her education was helped to aspire to and successfully go on to university education.

At the time I had no intention of going to university, but she (worker) said, 'Well why don't we put it in your Pathway Plan?' 
These young people were keen not to be fitted into a perceived high risk care leaver pathway.

I knew most of the kids that lived in these places (hostels) and they just weren't the sort of kids that I wanted to be associated with, like they were drug users and things like that.

Although some credit was given to residential staff for supporting these steps forward, distinctive for this young person (below) and others was the link to a supportive member of the birth family.

It is nice knowing that she (aunt) is there. It is kind of like a security and safe, because even though I have got a lot of people I can go to, this is an extra security. She doesn't have a file on me like a social worker does and things like that, she has experience of $\underline{\text { me }}$ rather than files.

These young people recognised the contribution of multiple others to their identity. But their resilience, given the losses they had experienced, was strongly linked to their sense of agency. As this young person put it:

Whereas most people have their morals and values imbedded in them by their parents, I have been brought up by so many different people that I have kind of created like my own person.

\section{Victim to survivor}

Narrative pathway

Narratives of early childhood for these young people focused on themselves as victims of abuse, neglect and rejection. Their move into care and into the residential setting was as a result of the behaviour and decisions of others. Although feelings about birth families were complex, the contrast between early maltreatment and subsequent good 
relationship experiences in residential care were reflected on as a form of 'rescue'. This led to a positive transformation during the teenage years from a victim identity to that of a survivor, someone who could connect with others and who had the agency to make choices. This adult identity included showing the world that they had changed and beaten expectations / become resilient by overcoming earlier adversities. Some vulnerabilities persisted, however, so although both agency and connection were present and narratives were coherent, surviving could be threatened in adulthood by loss of employment or relationships, with a risk of helplessness and victimhood resurfacing. An open door to support from residential and transitions workers remained necessary.

For these young people, histories of abuse in birth families had led to feelings of victimhood. But there was an additional sense of betrayal for those whose experiences in care replicated the rejection, and in some cases the abuse and neglect, from which they had been removed. It took a while to trust residential workers and to experience the benefits of relationships. Young people valued experiencing staff as 'people' not 'workers', which in turn could lead to a sense of being 'at home' with staff as 'family' or 'friends'.

When we started going on holiday together and I could see the guys out of work, I got the chance to understand them as people, not just as workers.

They were my second family, every single one of them, you know, they were who I counted on, still do to this day sometimes.

I had never had a best friend and when I was younger I used to class him (residential worker) as my best friend... He would come in, give me a high five, 
give me a hug and all that and like proper make me feel like I actually was at home.

For young people who had defined themselves as victims of others, becoming a survivor was linked to both a sense of agency and of connection. In adolescence, this was especially valuable if it led to success in age appropriate and constructive activity. One young person commented on the excitement of being offered a job after interview at the age of 16, a job she was still in four years later:

That is why I went for it! Proved everyone else wrong!

The value of staying connected after leaving care was linked to this sense of agency, supported by young people's sense of the staff's commitment to 'not giving up' them. They help you realise that you can do things and you might act like a spoiled brat and you might not want to go to school, you might get kicked out of school but they.... sort of try and tell you, 'You can do that'-they don't give up on you.

This young person's story (below) is of her gradual move from dependence to independence - in the context of the ongoing availability of a relationship with her transitions worker.

She's a lovely lady. If it weren't for her I probably still wouldn't be ringing up about the bills.... I would be like, 'You ring them, I don't want to ring them'... It got to the point like, 'No, I'll do it now, I'll do it.' But she'll still come round for coffee. I don't see her as often and I don't really notice that, but I think it's because I don't need her as much. I still think she is there if I need her. If I got really stuck in the dirt I can turn to her and just sort of say, 'I need help'. 
This young person's capacity to articulate this process of maturation suggests a coherent level of reflection that was a sign of her resilience. Her trust in the worker's availability and her own entitlement to support is what most young adults hope to get from their families.

\section{Victim to struggling}

\section{Narrative pathway}

For these young adults, childhood experiences and identities that focused on victimhood in the face of maltreatment in their families of origin had not been resolved, but seemed confirmed by accounts of subsequent experiences of victimhood in foster care, in adoption, in their peer group and, for some as they saw it, in residential care. Feeling singled out for rejection or bullied by others led to a persistent sense that life was unfair. Where their behaviour was difficult, this was explained as the consequence of excessive victimization. Their persistent emotional demands of others, who could never care enough, led to disappointment. There was a sense of inevitability and blame of others - so even a choice that they had made, for example to leave the children's home, could be seen as the fault of others, as being 'kicked out'.

A lack of agency and self doubt as young adults was sometimes defended against by claims of being 'special' but this was accompanied by a desperate need to connect, to belong and be loved. Inevitably young people were demanding of and sometimes grateful for transitions workers' time, but equally inevitably they could become disappointed when care was not immediately available and feelings of rejection and victimhood reappeared. A challenge for transitions workers was how to promote agency and autonomy for these young people while meeting their emotional needs. 
In the stories these young people told, as in the previous pathway, there were examples of negative experiences in care prior to arrival in the children's home that compounded negative experiences in birth families. For young people who had wanted to stay in a placement, the hardest feeling to resolve was feeling singled out for rejection.

Oh great, these carers are keeping my sister but not me - what is wrong with me?

Young people expressed ambivalence about people, including staff, in their lives. So there were positive accounts of residential workers who were 'mumsy' or 'like a mum' or 'really nice', but then there were references to being 'treated like a piece of dirt'. But often, as young adults who were now struggling, there were feelings of regret about what was lost.

If I felt stressed they would take me out for a drink ...and basically they was like a father and mother to us...it is hard to let go of them now.

For some, this was associated with a sense of anger.

They go on so much about like making family with them and then as soon as you have, you are kicked out and you are not allowed to see them when you go back.

But this switching from positive to negative, needy to angry, showed how hard it was for these young people to accept help and to establish a stable, supportive and coherent relationship with transition workers. Young people with this persistent sense of self as a victim had found it difficult while in care, even with the support of the residential staff, to make the transition to another type of identity.

Although their stories felt negative at this point in their lives, even for these young people there was some sense of a positive connection to staff at the agency, in the past or currently, which held out a possibility of being able to use support in the future. The 
main concerns here were that building a stable adult life might be threatened by challenges in establishing themselves in housing and employment while they lacked agency and the capacity to sustain relationships.

\section{4. 'Bad child' to survivor}

\section{Narrative pathway}

Narratives of childhood for these young people focussed on how what happened to them, including abuse, rejection and loss, was a result of their own behaviour. Bad things that happened were at some level their fault as a 'bad child'. Where anger against harmful or neglectful others was briefly expressed, the story soon turned back to self-blaming in ways that protected parents and others from blame. Language such as 'little devil' or 'little terror' was used to describe the childhood self. The fact that siblings remained at home was seen as evidence of their difference and the reason why parents or other family members rejected or could not cope with them.

Such stories for this group were followed by vivid accounts of the transformation experienced in the children's home. Staff were given credit for sticking by them in spite of their 'bad' behaviour and supporting them to change. Becoming a survivor for these young people was about discovering their own value through caring relationships. There were turning points as they started to behave better, to take responsibility for themselves and to build better lives as better people. For some young people the significant change into becoming more settled and a 'survivor' occurred in early adulthood with support from the transitions team. But as young adults their awareness of how far they had come and their belief in the organisation and the availability of transitions staff gave them some hope - in itself a resilience characteristic. Agency and connection based on a sense of belonging were both present, although some vulnerabilities and need for support inevitably continued. 
The defining characteristic for these young people was their accounts of what difficult, 'bad' children they had been from when they were young. I was about seven or eight - I was quite a nasty brawler.

This young person now regretted this childhood self.

I am not proud of my fights now. I look back on them and regret them, but at the time I wasn't afraid of no-one, it didn't matter what size they were to me.

He also recalled the consequence of his bad behaviour, being 'kicked out' of school. Subsequent losses led to family breakdown, in part, as he recalls it, because his own behaviour could not be coped with.

My granddad had died, which my mum then got into a distress and just couldn't cope. The whole family kind of shuddered apart.

A feature of this group, who were later able to achieve a change in their behaviour and sense of self-worth, was that their narratives included not only memories of their difficult behaviour but also the possibility of explanations that moderated their sense of self-blame.

I got diagnosed with ADHD at the age of five and learning difficulties. I was a little devil because I used to get my sister's head and smack it on the concrete or drown her in the swimming pool.

In other cases, explanations included some blame attributed to their parents.

My mum wasn't the nicest mum I had, where she was kicking me, slapping me and things like that. I didn't really want to say in case anything worse happened. 
When young people arrived in the children's home, they recalled their extreme

behaviour - though were able to link that to their distress.

The first few weeks...I was breaking out, fighting and punching the staff... I remember them having to restrain me in the car going down there because I was going that violent that I think it took four adults to hold me down... I am not proud but it was a distressing time definitely.

Where subsequent experiences in care had made a positive difference, young people could identify the benefit and the risks avoided.

Mum regrets it because she blames herself for all the stuff that happened, but I have said that is probably the best decision she has made... Personally I think I would probably have been in prison by now.

Changes in their behaviour were linked to building positive relationships. This young person describes a member of staff, 'like a dad', who helped him manage his stress and engage in constructive activity.

I loved (him) like a dad really.... Whenever I got stressed about something he was always there for me to go and talk to. My favourite memories of me and him were we always used to love going swimming....

One young person who was in steady employment in early adulthood, felt motivated by staff to take responsibility and earn his own living.

I didn't want to do anything, but then (home staff) had a good word with me: 'If you don't do this you are not going to succeed in life, you are just going to be on benefits and all that...'. And I thought to myself, I don't want to be doing that. 
The availability of staff to help these young people manage the stress that triggered difficult behaviour continued once young people had left care - for some, this was a key part of the transitions service support.

My support worker was there one time when I was like really upset because I had a really bad argument with people I used to live with and no one could have calmed me down apart from (staff) so I like texted them and said 'Can you ring me because I can't calm myself down? I'm like really upset'.

Surviving as young adults owed a great deal to the changes in their behaviour and their capacity to use support, but their ability to reflect coherently on these changes and articulate the reasons for them suggested important resilience characteristics.

\section{5. 'Bad child' to struggling}

Narrative pathway

These narratives were also dominated by young peoples' sense of themselves as 'bad children' who had caused or deserved rejection or removal into care, in spite of histories suggesting that they were also victims of maltreatment and loss. Unlike the previous group, however, for these young adults the sense of badness and self-blame persisted, with some positive experiences in the care organisation but no significant transformation experience. They described their behaviour as leading to them being 'kicked out' of the children's home with stories of subsequent downward spirals that included self harm and drug use. They blamed their own behaviour for losing their place in the care organisation and either longed to keep the connection with transitions workers and other staff or maintained an angry and resentful stance against everyone including the care organisation - or both. 
Memories of childhood aggression and bad behaviour were linked to justifications rather than regret as in the previous group.

I used to beat pupils up in town I really did - can't stand disrespect.

Even when a young person reported having been assured that coming into care was not their fault, they 'saw' that it was.

Well kind of in some way it must be my fault you know. I must have done something wrong....The reason why I see I went into care is because of me, because I was so naughty...

Even though these young people remained troubled as adults, they had some positive memories and some had found greater stability in the children's home than in previous placements.

I could just sit there and talk to him (worker) about anything and he don't judge you.

Two and a half years - the longest place I stayed. It was welcoming.

In early adulthood, one of the most painful feelings to manage, therefore, was the regret that because of their bad behaviour, as they saw it, they had lost an opportunity to change and find a better life.

Living on my own, being homeless and that through the time of leaving (the home) messed with my head and if I had never left I would be fine, I would have a job or I would be driving but I was stupid and got kicked out.

But this person's regret (above) was based on a sense of responsibility not reflected in other young people who saw their violence as beyond their control. 
My actions are completely beyond my control...I can punch someone in the face and not even realise that I have done it until after I have done and no anger there just pumph...

However, even for this group there were still some signs of hope in that ties to the organisation were acknowledged.

\section{Discussion}

The young people's narrative pathways demonstrated a number of important themes which have implications for practice in supporting young people through residential care and the transition to adulthood.

The first was that the different narratives, in particular the specific ways in which young people defined themselves and their situation earlier in childhood, continued to have an impact during adolescence and in adulthood. Very powerful in these accounts was the fact that some young people with adverse backgrounds had experienced significant transformations in the way in which they defined their sense of self - for example, the ability to move on from defining themselves as a victim. Their identity could be refashioned in preparation for a more successful transition to adulthood. But equally, some young people were still struggling with patterns of troubled behaviour as they attempted to engage with the adult world of relationships and work. As Stein (2012) has pointed out, however, a study of this kind can only capture a young person's capacity to move on successfully at that point in time - promising pathways may suffer setbacks, just as young people who are currently struggling may find a way to stabilize their lives if they meet a stable partner or find a supportive work environment. 
So the message of these narrative pathways, as Gilligan's work on resilience (1999) would suggest, is that we need to consider the factors that may sustain or create more positive pathways. It seemed that the resilience dimensions identified above i.e. connection, agency, activity and coherence, were underpinning the different patterns in young people's narrative pathways and in particular the capacity to benefit from the residential care experience and manage the transition to adulthood. Although these themes were arrived at inductively from the data they fitted well with theories and research on resilience (Rutter 2013; Masten 2014), especially in relation to care experiences (Gilligan 1999; Schofield \& Beek 2005).

The most striking, and perhaps surprising in the residential care context, was the way in which connection in terms of close trusting relationships with residential and transitions staff was defined in terms of family - with staff described as like family, as mums and dads, also commented on by Kendrick (2013) . Reflected here was the way in which our shared cultural meanings for family are drawn on to capture the emotional feelings of being cared about and cared for and to create a continuous connection into adulthood. The feeling that both residential and transitions staff were committed to 'being there' for them beyond leaving care was a major feature of successful transformation narratives and this secure base was built on their sense of family relationships and belonging (Schofield \& Beek 2009; Schofield et al 2015). Young people who were struggling, both those defining themselves as victims or 'bad children', were often preoccupied with the relationships and opportunities for connection they had lost rather than being indifferent to them. The significance of relationships and belonging in residential care has been highlighted by Hart et al (2015) but is also relevant in thinking about residential care as offering 'permanence' (Schofield et al 2015). 
Agency or self-efficacy, associated with resilience (Masten 2014), had very different meanings to young people who felt they were victims compared to those who had felt powerfully 'bad' because of their antisocial behaviour. Being in care is always ambiguous in relation to power, with young people at times feeling powerless when decisions are made about them, but at times too powerful in breaking placements. Gaining an appropriate sense of agency while in residential care and during transitions was linked to positive transformations, but also invariably linked to stories of trust and connection in relationships.

As in previous studies (Gilligan 1999; Schofield and Beek 2005; Berridge et al 2012), the references to education, to sport and to employment reflected the fact that young people who had changed positively were engaged in constructive activities. But other resilience dimensions interacted to achieve this outcome. For young people who had experienced their childhood as victims, the ability to achieve in education or work was linked both to their capacity to make trusting relationships and to feel more in control of their lives, with a greater sense of agency.

The coherence of narratives is significant in thinking about identity construction especially for young people with complex histories in which explanations of causality would always be uncertain and feelings mixed. Erikson (1968) suggests adolescent identity achievement occurs after a period of exploration or 'moratorium'. The exploration for these young people included addressing a range of very big questions about the kind of parents they had and the kind of child they must have been to end up in care. For those young people who were able to draw on the positive messages of love, support and hope from staff, it was possible to develop and believe a story that helped them to accept mixed feelings about their birth family and to gain confidence in themselves and their potential. 
One gap in the literature mentioned earlier concerned how close relationships in residential care can contribute to a sense of permanence, security and belonging (Department for Education 2015b: para 2.6). Remarkable in this study was the way in which residential staff were perceived by young people as emotionally available and as providing a sense of family. This new way of thinking about residential care was made possible by the quality and continuity of relationships that these young people experienced. This link between residential care and permanence would be an important focus of further research.

\section{Conclusion}

Although the sample size and representativeness are limitations of this study, it was still possible through use of narrative analysis to demonstrate the different ways in which young people construct and give meanings to their childhood and adolescent experiences, both the loss and distress and the possibility for resilience and growth when leaving care (Stein 2012).

A key message for practitioners is that listening to the different underlying meanings to young people of their apparently similar stories of adverse childhoods is an important first step in helping them to make sense of how and why they may be finding it difficult to accept help, form relationships, become more resilient and move on.

Residential care has much to contribute to young people's lives and its role as 'last resort' needs to be reviewed. At a time when policy on residential care is stressing its short term role, it is clear from this study that continuity of care and longer term commitment from residential and transitions staff, often though of as 'family', can 
enable young people with very different life narratives to construct a positive identity and grow in resilience in the context of security and belonging.

\section{REFERENCES}

Bamberg, M. (2006) Stories: Big or Small. Narrative Inquiry, 16 (1) 139-147.

Berridge, D., Biehal N. \& Henry, L. (2012) Living in Children's Residential Homes. DFERR201, University of Bristol.

Crossley, M. L. (2000) Introducing Narrative Psychology: Self, Trauma and the Construction of Meaning. Open University Press, Buckingham.

Department for Education (2013) Staying put: arrangements for Care Leavers aged 18 and above to stay on with their former foster carers. Department for Education, London. Department for Education (2015a) Children looked after in England including adoption. Department for Education, London.

Department for Education (2015b) Amendments to the Children Act 1989 Guidance: Care Planning, Placement and Case Review. (Volume 2) Department for Education, London Erikson, E. (1968) Identity, Youth and Crisis. W.W Norton and Company, New York. Freeman, M. (2004) Data are everywhere: Narrative criticism in the literature of experience. In: Narrative Analysis. Studying the Development of Individuals in Society. (eds C. Daiute \& C. Lightfoot) Sage Publications, Thousand Oaks, CA. Freeman, M. (2006) Life 'on holiday'? Narrative Inquiry 16 (1) 131-138.

Gergen, K. J. and Gergen, M. M. (1983) Narratives of the Self. In: Studies in Social Identity (eds T. Sarbin \& K. E. Scheibe). pp. 254-273. Praeger, New York.

Gilligan, R. (1999) Enhancing the resilience of children and young people in public care by mentoring their talents and interests. Child \& Family Social Work 4 (3) 187-196. Hart, D. and La Valle, I., with Holmes, L. (2015) The place of residential care in the English child welfare system Department for Education, London. 
Holland, S., Renold, E., Ross, N. \& Hillman, A. (2008) The everyday lives of children in care: using a sociological perspective to inform social work practice ESRC National Centre for Research Methods Working Paper Series 1/08.

Howe, D. (2005) Child Abuse and Neglect: Attachment, Development and Intervention. Palgrave Macmillan, Basingstoke.

Kendrick, A. (2013) Relations, relationships and relatedness: Residential child care and the family metaphor, Child and Family Social Work, 18 (1): 77-86.

Masten, A. (2014) Ordinary Magic: Resilience in Development. The Guilford Press, New York.

McAdams, D. P. (1993) The Stories We Live By: Personal Myths and the Making of the Self. The Guilford Press, New York.

Meltzer, H., Gatward R., Goodman, R. \& Ford, T. (2000) The Mental Health of Children and Adolescents in Great Britain. The Stationery Office, London.

Mishler, E. G. (1995) Models of Narrative Analysis: A Typology. Journal of Narrative and Life History 5 (2) 87-123.

National Children's Bureau (2014) 'Staying Put' for young people in residential care: A Scoping Exercise. National Children's Bureau, London

Phoenix, A. (2013) Analysis of narrative contexts. In: Doing Narrative Research. Second Edition. (eds M. Andrews, C. Squire \& M. Tamboukou) pp. 64-77. Sage Publications, London.

Riessman, C. (1990) Strategic uses of narrative in the presentation of self and illness: A Research Note. Social Science \& Medicine 30 (11)1195-1200.

Riessman, C. (1993) Narrative Analysis. Sage Publications, Thousand Oaks, CA. Rutter M. (2013) Annual Research Review: Resilience - clinical implications. Journal of Child Psychology and Psychiatry 54 (4) $474-487$

Schofield G \& Beek M (2005) Risk and resilience in long-term foster care British Journal of Social Work 35 (8) 1283-1301. 
Schofield G. \& Beek M. (2009) Growing up in foster care: providing a secure base through adolescence Child and Family Social Work 14 (3), p255 - 266

Schofield G., Ward E \& Larsson B. (2015) Moving on - but staying connected: An exploration of young people's transitions from Break and the role of the Moving On team Norwich, Centre for Research on Children and Families: University of East Anglia. Stein M. (2012) Young People Leaving Care: Supporting Pathways to Adulthood. Jessica Kingsley Publishers, London.

Thoburn, J. and Ainsworth, F. (2014) Making sense of differential cross-national placement rates for therapeutic residential foster care. In: Therapeutic Residential Care for Children and Youth (eds J. K. Whitaker, J. del Valle \& L. Holmes.) Jessica Kingsley, London

Wengraf, T. (2001) Qualitative Research Interviewing. London: Sage Publications 